\section{Readmission after hospitalization for heart failure in elderly patients in Chapidze Emergency Cardiology Center, Georgia}

Readmission after hospitalization

Tengiz Verulava

School of Medicine and Healthcare Management, Caucasus University, Tbilisi, Georgia and Faculty of Social and Political Sciences, Ivane Javakhishvili Tbilisi State University, Tbilisi, Georgia

Revaz Jorbenadze

Chapidze Emergency Cardiology Center, Tbilisi, Georgia

Ana Lordkipanidze

Faculty of Social and Political Sciences, Ivane Javakhishvili Tbilisi State University, Tbilisi, Georgia

Ana Gongadze

School of Medicine and Healthcare Management, Caucasus University,

Tbilisi, Georgia, and

Michael Tsverava and Manana Donjashvili

Chapidze Emergency Cardiology Center, Tbilisi, Georgia
Received 20 July 2020 Revised 9 November 2020 2 December 2020 10 December 2020 Accepted 21 December 2020

\begin{abstract}
Purpose - Heart Failure (HF) is one of the leading mortality causes in elderly people. The purpose of this study is to assess readmission rates and reasons in elderly patients with $\mathrm{HF}$.

Design/methodology/approach - The authors explored medical records of elderly patients with HF (75 years and more) at Chapidze Emergency Cardiology Center (Georgia) from 2015 to 2019. The authors analyzed the structure of the cardiovascular diseases and readmission rates of hospitalized patients with $\mathrm{HF}$ (I50, I50.0 I50.1). A multivariate logistic regression model was used to identify factors, associated with readmission for any reason during 6-9 months after the initial hospitalization for $\mathrm{HF}$.

Findings - The major complication of cardiovascular diseases in elderly patients is $\mathrm{HF}(68.6 \%)$. Hospitalization rates due to $\mathrm{HF}$ in elderly patients have increased in recent years, which is associated with the population aging process. This trend will be most likely continue. Despite significant improvements in HF treatment, readmission rates are still high. $\mathrm{HF}$ is the most commonly revealed cause of readmission ( $48 \%$ of all readmissions). About 6-9 months after the primary hospitalization due to $\mathrm{HF}$, readmission for any reason was $60 \%$. Patients had concomitant diseases, including hypertension (43\%), myocardial infarction (14\%), diabetes $(36 \%)$ and stroke $(8 \%)$, affecting the readmission rate.

Originality/value - HF remains an important problem in public health. During HF-associated hospitalizations, both cardiac and non-cardiac conditions should be addressed, which has the potential for
\end{abstract}

(C) Tengiz Verulava, Revaz Jorbenadze, Ana Lordkipanidze, Ana Gongadze, Michael Tsverava and Manana Donjashvili. Published in Journal of Health Research. Published by Emerald Publishing Limited. This article is published under the Creative Commons Attribution (CC BY 4.0) licence. Anyone may reproduce, distribute, translate and create derivative works of this article (for both commercial and non-commercial purposes), subject to full attribution to the original publication and authors. The full terms of this licence may be seen at http://creativecommons.org/licences/by/4.0/legalcode 
JHR

36,3

health problems and disease progression. Some readmissions may be prevented by the proper selection of medicines and monitoring.

Keywords Heart failure, Readmission, Hospitalization, Aging, Georgia

Paper type Research paper

\section{Introduction}

Heart failure (HF) is a large and increasing problem worldwide, causing high morbidity and mortality and requiring expensive treatment. Around 17.0 million people died from cardiovascular diseases in 2016, accounting for $31.4 \%$ of mortality [1]. Approximately 66,670 patients have HF in Georgia (150 per 100,000 population), annually more than 7,330 people are initially diagnosed with it and the mortality rate is $1 \%$ [2].

The studies report that HF incidence and mortality risk from initial hospitalization is higher in males than in females [3]. The outcomes for patients with HF are unfavorable. Half the patients die within four years, and in the case of a severe form of $\mathrm{HF}, 50 \%$ of patients die within the first year.

The achievements in HF diagnostics and treatment during the past decade resulted in an increase in life expectancy and population aging, which, in turn, increased prevalence. Studies prove that HF incidence and mortality have reduced since the 1990s [4]. This is significantly because of the use of medicines such as angiotensin-converting enzyme inhibitors, beta-blockers and aldosterone antagonists. After the initial diagnosis of $\mathrm{HF}$, the estimated life expectancy during one year is $72-75 \%$, and in five years is $35-52 \%$ [5].

An increase in patients' life expectancy and accordingly, the population aging process, progress in ischemic heart disease and hypertension treatment have promoted an increase in the number of patients with HF during the past two decades [6]. In patients with HF, age is associated with an increased risk of cardiovascular diseases and mortality rate. Studies report that the hospitalization rate of patients with HF is higher above 65 years [7]. Low degrees of physical activity and depression and anxiety in elderly patients increase disease risk and aggravates its clinical results [8].

Studies report that patients hospitalized for HF have a high risk of readmission [9]. The major reason for most of the readmission cases were other, non-cardiovascular diseases, like respiratory tract infections, kidney disorders, indicating the spread of concomitant diseases in patients with HF. Elderly patients with HF are mostly observed to have concomitant chronic diseases (hypertension, atrial fibrillation, peripheral vascular disease, coronary artery disease, valvular disease, respiratory tract disease, kidney failure) [10].

The prognosis of the elderly patients with HF emphasizes the importance of the methods of prevention strategies, early detection and treatment, which can prevent myocardial disfunction, especially for people with a high risk of developing HF due to hypertension, diabetes or myocardial infarction.

The major problems in elderly patients with $\mathrm{HF}$ are not adhering to modern clinical recommendations, incomplete usage of medicines or inaccurate dosage [11]. Therefore, patients with HF frequently do not benefit from effective treatment regimens due to the above. In this regard, adherence to the proper treatment conditions is essential for patients with HF. It is also important that patients should be involved in the clinical decision-making process regarding their treatment.

Comprehensive planning of discharge, including consultation regarding taking medications and their revision, improved communication between patient and doctor and further continuous surveillance, can promote a readmission reduction. However, usage of cardiac implants together with optimal medicinal treatment successfully reduces hospitalization rates for patients with $\mathrm{HF}$ [12].

Studies report that elderly patients with $\mathrm{HF}$ are rarely included in randomized controlled trials [13]. Therefore, data about them are limited. Despite the important changes in HF 
management during recent years, little is known about the outcomes in elderly patients with HF. The goal of our study was the assessment of readmission in elderly patients with HF.

\section{Methodology}

We obtained all hospital claims records of 75-year-old and older patients with cardiovascular diseases treated in Chapidze Emergency Cardiology Center (Tbilisi, Georgia) between 2015 and 2019. Hospital claims included admission and discharge dates, sex, age and International Classification of Diseases (ICD-9) I00-I99 codes for cardiovascular diseases.

Readmission rates for hospitalized patients with $\mathrm{HF}$ were studied by the following codes: I50 HF, I 50.0 congestive heart failure, I50.1 left ventricular heart failure, I50.9 HF, not specified. Readmission rates of elderly patients with $\mathrm{HF}$ were assessed by the age group and hospitalization years. Readmission was assessed since the discharge day.

Patients were divided into categories by age group (75-80 years old, 81-85 years old, 8690 years old and more than 90 years old), to compare within the elderly age group.

Besides the age, patient features included hospitalization for cardiovascular diseases (I00 I99), hospitalization for HF (I50, I50.0, I50.1, I50.9), hospital stay duration, concomitant diseases.

A multivariate logistic regression model was used to identify factors, associated with readmission for any reason during 6-9 months after the initial hospitalization for HF. Readmission for any reason during 6-9 months after the initial hospitalization for HF was taken as a dependent variable. Independent variables included: age, gender, length of stay during the initial hospitalization, concomitant diseases, cardiac device implantation during initial hospitalization for $\mathrm{HF}$, hospitalization during 6-9 months period before the initial hospitalization for $\mathrm{HF}$ and hospitalization for $\mathrm{HF}$ during the previous calendar year.

Statistical analyses were done on the basis of the social statistics program SPSS.

\section{Ethical issue}

This study passed the ethical review from the Health Research Ethics Committee of the Health Policy Institute numbered 36/5/12/2019.

\section{Results}

Our study showed that between 2015 and 2019, 8,623 patients aged 75 years and older with cardiovascular diseases (ICD10 - I00-I99) had received treatment in the Emergency Cardiology Center. Further, 9,916 hospitalization cases occurred within this period. From the cardiovascular system diseases, angina pectoris (43.83\%) and acute myocardial infarction $(12.54 \%$ ) were mostly observed in elderly patients (Table 1 ). Most patients were aged $75-80$

\begin{tabular}{|c|c|c|c|c|}
\hline & Nosological groups & $n$ & $\%$ & \\
\hline $\mathrm{I} 20$ & Angina (angina pectoris) & 3,780 & 43.83 & \\
\hline $\mathrm{I} 21$ & Acute myocardial infarction & 1,082 & 12.54 & \\
\hline $\mathrm{I} 35$ & Non-rheumatic lesions of the aortic valve & 605 & 7.02 & \\
\hline $\mathrm{I} 25$ & Chronic ischemic heart disease & 593 & 6.87 & Table 1 \\
\hline $\mathrm{I} 11$ & Hypertensive heart disease & 511 & 5.93 & $\begin{array}{r}\text { I able } \mathbf{1 .} \\
\text { Cardiovascular system }\end{array}$ \\
\hline I08 & Simultaneous damage to several valves & 430 & 4.99 & diseases (I00-199) by \\
\hline \multirow[t]{3}{*}{$\mathrm{I} 34$} & Non-rheumatic lesions of the mitral cells & 426 & 4.94 & nosological groups in \\
\hline & Other diseases & 1,196 & 13.88 & elderly patients \\
\hline & Total cases of cardiovascular system diseases & 8,623 & 100 & (2015-2019) \\
\hline
\end{tabular}

Readmission after hospitalization 
JHR

36,3

\section{8}

years $(64.6 \%)$ and were male $(63.6 \%)$; however, with age, the number of female patients increased.

Of the patients with cardiovascular diseases, 5,912 patients $(68.6 \%)$ had complications due to HF. Further, 7,508 hospitalization cases for HF were observed within this period. The intrahospital mortality rate associated with initial hospitalization for HF was $1.8 \%$. The results reported in the study are based on survived patients after the initial hospitalization for $\mathrm{HF}$.

In the 6-9-month period before the initial hospitalization, $43 \%$ of patients $(n=2,542)$ had one or more hospitalizations for any reason. Hospitalization for $\mathrm{HF}$ during the previous calendar year was observed in $14 \%$ of patients $(n=828)$. The data of hospitalized patients with $\mathrm{HF}$ are presented in Table 2 . The majority of the patients with HF were people aged 7580 years $(n=3,614,61 \%)$ and males $(n=3,665,62 \%)$. The average length of stay of the hospitalized patients with HF was $5.2 \pm 5.1$ days, approximately $82 \%$ of patients $(n=4848)$ were hospitalized for $\leq 7$ days. Also, $56 \%$ of patients had coronary arteries disease, $47 \%-$ hypertension, $35 \%$ - diabetes. $0.8 \%$ of patients had cardiac implants during the hospitalization for HF.

Most of the HF-associated diseases were reported for left ventricular failure $(n=3,843$, $65 \%$ ). The study reported that the number of hospitalizations of elderly patients with $\mathrm{HF}$ increased, but the dynamics had a more wavy pattern (Table 3). Further, 6-9 months after the hospitalization for $\mathrm{HF}$ in $56 \%$ of patients $(n=3,311)$, minimum of one readmission was observed, with an average of 1.9 readmissions per each patient (Table 4). The most common cause for readmission during this period was $\mathrm{HF}$ ( $48 \%$ of all readmissions). Also, 6-9 months after the initial hospitalization for $\mathrm{HF}$, readmission for any reason was $60 \%$. The second and

\begin{tabular}{|c|c|c|}
\hline & $n$ & $\%$ \\
\hline \multicolumn{3}{|l|}{ Age (years) } \\
\hline $75-80$ & 3,614 & 61 \\
\hline $81-85$ & 1,579 & 27 \\
\hline $86-90$ & 628 & 11 \\
\hline$\geq 90$ & 91 & 1 \\
\hline Total & 5,912 & 100 \\
\hline \multicolumn{3}{|l|}{$\operatorname{Sex}$} \\
\hline Female & 2,247 & 38 \\
\hline Male & 3,665 & 62 \\
\hline \multicolumn{3}{|l|}{ Initial hospital stay duration } \\
\hline \multicolumn{3}{|l|}{ Average $\pm \mathrm{SD}$} \\
\hline$\leq 7$ days & $5.2 \pm 5.14848$ & 82 \\
\hline$>7$ days & 1,064 & 18 \\
\hline \multicolumn{3}{|l|}{ Concomitant diseases (respondent could have more than one disease) } \\
\hline Diabetes & 2,069 & 35 \\
\hline Hypertension & 2,779 & 47 \\
\hline Myocardial infarction & 1,005 & 17 \\
\hline Stroke & 355 & 6 \\
\hline Coronary arteries disease & 3,311 & 56 \\
\hline Peripheric vascular disease & 296 & 5 \\
\hline Cardiac device implantation during initial hospitalization for $\mathrm{HF}^{* * * *}$ & 47 & 0. \\
\hline Hospitalization during 6-9 months before the initial hospitalization for HF & 2,542 & 43 \\
\hline Hospitalization for HF during the previous calendar year & 828 & 14 \\
\hline
\end{tabular}

Table 2.

HF complications in elderly patients with cardiovascular system diseases, by age
Note(s): ***Pacemaker implantation, cardioverter defibrillator implantation, resynchronizer implantation 


\begin{tabular}{|c|c|c|c|c|c|c|}
\hline & $\begin{array}{c}\text { All }(n=5,912 \\
100 \%)\end{array}$ & $\begin{array}{c}75-80 \mathrm{y} / \mathrm{o} \\
(n=3,614 ; 61 \%)\end{array}$ & $\begin{array}{c}81-85 \mathrm{y} / \mathrm{o} \\
(n=1,579 ; 27 \%) \\
\end{array}$ & $\begin{array}{c}86-90 \mathrm{y} / \mathrm{o} \\
(n=628 ; 11 \%) \\
\end{array}$ & $\begin{array}{c}>90 \mathrm{y} / \mathrm{o} \\
(n=91 ; 1 \%) \\
\end{array}$ & $\begin{array}{r}\text { Readmission } \\
\text { after }\end{array}$ \\
\hline $\begin{array}{l}\text { I50.0 congestive } \\
\text { heart failure }\end{array}$ & $578(9.8)$ & $412(11.4)$ & $116(7.3)$ & $43(6.8)$ & $7(7.7)$ & \\
\hline 2019 & $198(100)$ & $112(56.6)$ & $64(32.3)$ & $18(9.1)$ & $4(2)$ & \\
\hline 2018 & $83(100)$ & $48(57.7)$ & $22(26.6)$ & $11(13.3)$ & $2(2.4)$ & \\
\hline 2017 & $57(100)$ & $35(61.4)$ & $11(19.3)$ & $11(19.3)$ & 0 & 579 \\
\hline 2016 & $166(100)$ & 166 (100) & 0 & 0 & 0 & \\
\hline 2015 & $74(100)$ & $51(68.9)$ & $19(25.7)$ & $3(4.1)$ & $1(1.3)$ & \\
\hline $\begin{array}{l}\text { I50.1 left } \\
\text { ventricular heart } \\
\text { failure }\end{array}$ & $3,843(65)$ & 2,217 (61.3) & $1,137(72)$ & $441(70.2)$ & $48(52.7)$ & \\
\hline 2019 & $825(100)$ & $405(49.1)$ & 301 (36.5) & $103(12.5)$ & $16(1.9)$ & \\
\hline 2018 & $763(100)$ & 494 (64.7) & $190(24.9)$ & $76(10)$ & $3(0.4)$ & \\
\hline 2017 & $900(100)$ & 586 (65.1) & $217(24.1)$ & $84(9.3)$ & $13(1.5)$ & \\
\hline 2016 & $940(100)$ & $462(49.1)$ & $331(35.2)$ & 139 (14.8) & $8(0.9)$ & \\
\hline 2015 & $415(100)$ & $270(65.1)$ & $98(23.6)$ & $39(9.4)$ & $8(1.9)$ & \\
\hline $\begin{array}{l}\text { I50.9 HF, not } \\
\text { specified }\end{array}$ & $1491(25.2)$ & 985 (27.3) & $326(20.7)$ & $144(23)$ & $36(39.6)$ & Table 3. \\
\hline 2019 & $262(100)$ & $165(63)$ & $74(28.2)$ & $18(6.9)$ & $5(1.9)$ & complications in \\
\hline 2018 & $348(100)$ & $219(62.9)$ & $82(23.6)$ & 40 (11.5) & 7 (2) & elderly patients with \\
\hline 2017 & $412(100)$ & $258(62.6)$ & $92(22.3)$ & $51(12.4)$ & $11(2.7)$ & cardiovascular system \\
\hline 2016 & 134 (100) & 117 (87.3) & 0 & $9(6.7)$ & $8(6)$ & disease, by age \\
\hline 2015 & 335 (100) & $226(67.5)$ & $78(23.3)$ & $26(7.7)$ & $5(1.5)$ & and years \\
\hline
\end{tabular}

third most common causes of readmission were pneumonia and aggravated chronic obstructive pulmonary disease, respectively.

Table 4 compares data of those patients with readmission during 6-9 months with the data of the survived patients and without readmission. Patients with the readmission after the initial hospitalization for HF had a greater length of stay during the initial hospitalization; they were more often hospitalized during previous years and had coronary artery disease, diabetes, peripheral vascular disease, stroke. These patients had fewer cardiac implants during the initial hospitalization for HF.

A multivariate logistic regression model was used to identify the factors associated with readmission for any reason during 6-9 months after the initial hospitalization for HF (Table 5). Dead patients were excluded from the study. The model demonstrated that age was one of the most important factors in readmission after 6-9 months. Patients aged 75-80 had an increased likelihood of readmission compared with patients between 81 and 90 years of age. Other factors associated with an increase in readmission include males, length of stay for more than seven days, coronary artery disease, hospitalization during 6-9 month period before the initial hospitalization for $\mathrm{HF}$ and hospitalization for $\mathrm{HF}$ during the previous year.

\section{Discussion}

Retrospective analyses of the elderly patients after the initial hospitalization due to HF report that despite important achievements in $\mathrm{HF}$ treatment, the readmission rate is still high. The most common reason for readmission is $\mathrm{HF}$ ( $48 \%$ of all readmissions). Similar rates are reported by other studies [14]. However, this rate significantly exceeds the rates reported by other studies [15]. The readmission rate for all reasons in 6-9 months after the initial hospitalization due to $\mathrm{HF}$ was $60 \%$. Similar results were reported by other studies [16]. 
Patients with readmission during 6-9 months $(n=3,311 ; 56 \%)$
Survived patients and without readmission during 6-9 months $(n=2,601 ; 44 \%)$

\begin{tabular}{|c|c|c|c|}
\hline 580 & $\begin{array}{l}\text { Age (years) } \\
75-80 \\
81-85 \\
86-90 \\
\geq 90 \\
\text { Total }\end{array}$ & $\begin{array}{c}1,192(36 \%) \\
927(28 \%) \\
795(24 \%) \\
397(12 \%) \\
3,311(100 \%)\end{array}$ & $\begin{array}{r}1,015(39 \%) \\
650(25 \%) \\
520(20 \%) \\
416(16 \%) \\
2,601(100 \%)\end{array}$ \\
\hline \multirow{6}{*}{$\begin{array}{l}\text { Table } 4 \text {. } \\
\text { Comparison of } \\
\text { patients' data with } \\
\text { readmission with the } \\
\text { data of the survived } \\
\text { patients and without } \\
\text { readmission during } \\
6-9 \text { months since the } \\
\text { first hospitalization }\end{array}$} & $\begin{array}{l}\text { Sex } \\
\text { Female } \\
\text { Male }\end{array}$ & $\begin{array}{l}1,035(31 \%) \\
2,276(69 \%)\end{array}$ & $\begin{array}{l}1,212(47 \%) \\
1,389(53 \%)\end{array}$ \\
\hline & $\begin{array}{l}\text { Length of stay during the initial hospita } \\
\text { Average } \pm \mathrm{SD} \\
\leq 7 \text { days } \\
>7 \text { days } \\
\text { Concomitant diseases }\end{array}$ & $\begin{array}{c}5.6 \pm 5.8 \\
2,417(73 \%) \\
894(27 \%)\end{array}$ & $\begin{array}{r}4.2 \pm 3.1 \\
2,159(83 \%) \\
442(17 \%)\end{array}$ \\
\hline & $\begin{array}{ll}\text { (1) } & \text { Diabetes } \\
\text { (2) } & \text { Hypertension } \\
\text { (3) } & \text { Myocardial infarction } \\
\text { (4) } & \text { Stroke } \\
\text { (5) } & \text { Coronary arteries disease } \\
\text { (6) } & \text { Prinheri } \text { }\end{array}$ & $\begin{array}{l}1,192(36 \%) \\
1,424(43 \%) \\
464(14 \%) \\
265(8 \%) \\
199(6 \%) \\
232(7 \%)\end{array}$ & $\begin{array}{r}884(34 \%) \\
1,353(52 \%) \\
286(11 \%) \\
208(8 \%) \\
104(4 \%) \\
156(6 \%)\end{array}$ \\
\hline & $\begin{array}{l}\text { (6) Perpheric vascular disease } \\
\text { Cardiac device implantation during } \\
\text { initial hospitalization for } \mathrm{HF}^{* * *}\end{array}$ & $26(0.8 \%)$ & $34(1.3 \%)$ \\
\hline & $\begin{array}{l}\text { Hospitalization during } 6-9 \text { months } \\
\text { period before the initial hospitalization } \\
\text { for } \mathrm{HF}\end{array}$ & $1,755(53 \%)$ & $1,092(42 \%)$ \\
\hline & $\begin{array}{l}\text { Hospitalization for } \mathrm{HF} \text { during the } \\
\text { previous calendar year }\end{array}$ & $795(24 \%)$ & $390(15 \%)$ \\
\hline
\end{tabular}

The second and third reasons for readmission were pneumonia and exacerbation of chronic obstructive pulmonary disease, respectively. Patients reported concomitant diseases, like hypertension (43\%), myocardial infarction (14\%), diabetes (36\%), peripheral vascular disease $(7 \%)$ and stroke $(8 \%)$, affected the readmission rate. Similar results were reported by other studies [17]. This indicates that readmission may be caused by non-cardiac conditions such as pneumonia, kidney failure and chronic obstructive pulmonary diseases. Studies report that non-selective receptor antagonists may aggravate chronic obstructive pulmonary disease and after initiating treatment for systolic heart failure, elderly patients may have more adverse events [18]. Some readmissions caused by non-cardiac reasons may be prevented by the proper selection of medicines and monitoring. Besides, elderly patients are in the high-risk group for hospital-acquired infections. Accordingly, preventive measures against elderly patients may reduce pneumonia-associated readmission cases [19]. Thus, both cardiac and non-cardiac conditions should be considered during HF-associated hospitalization in elderly patients.

The study reported that more than $80-90 \%$ of the patients with HF were discharged home after hospitalization [20]. The intrahospital mortality rate associated with initial hospitalization for $\mathrm{HF}$ was $1.8 \%$, and the average length of stay for the initial hospitalization was $5.2 \pm 5.1$ days. This rate is significantly lower compared to the results of other studies [21]. 


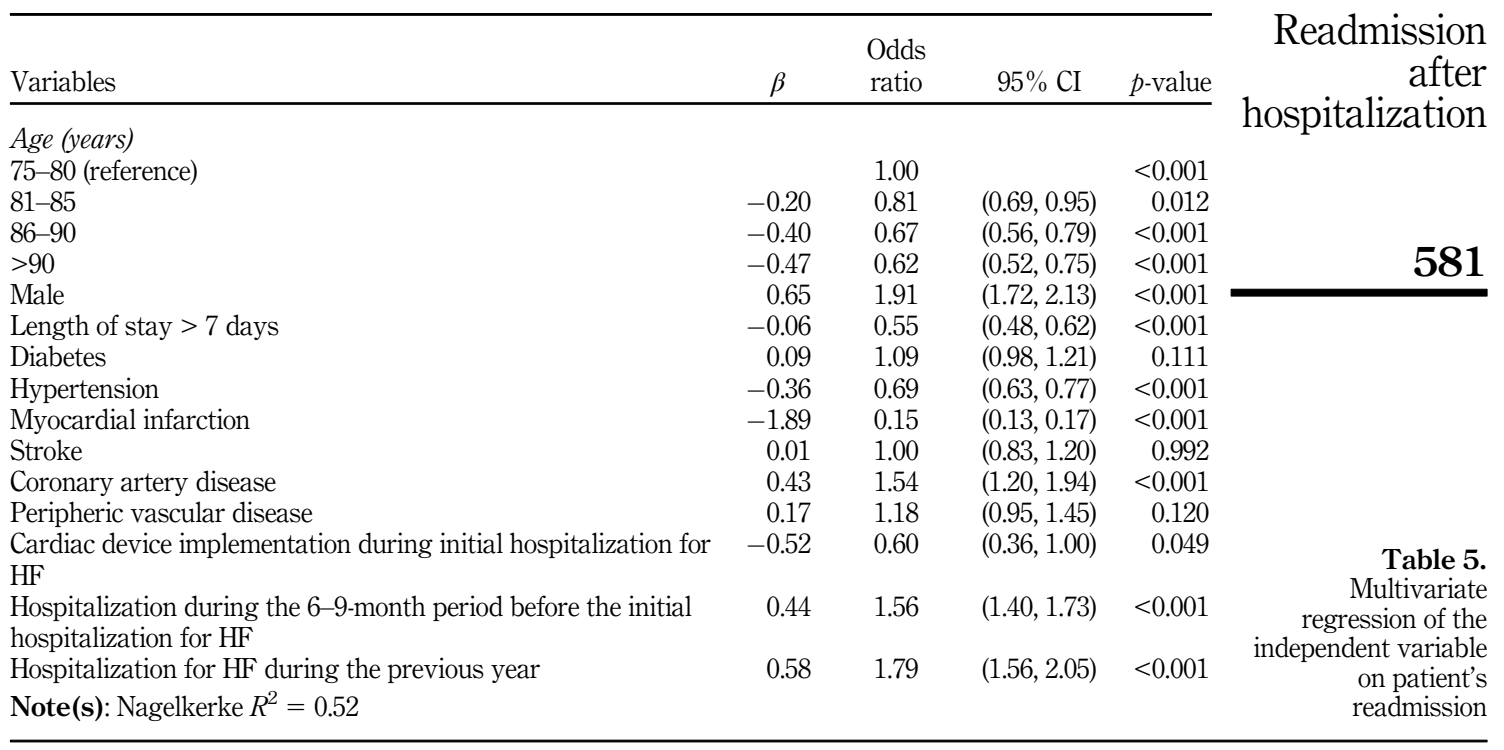

The study reported that patients without cardiac implants during initial hospitalization for $\mathrm{HF}$ had higher rates of readmission and mortality; however, the result was not statistically significant, probably due to the low number of observations.

The research showed that $\mathrm{HF}$ is a major complication of circulatory system diseases $(68.6 \%)$, and the most common of these diseases is HF syndrome due to ventricular failure $(65 \%)$. The study proved that hospitalization rates in elderly patients with HF increased, which is associated with the population aging process. This trend is likely to continue in the next years.

\section{Conclusion}

Our study proves that the number of hospitalizations for HF increased in the elderly population, which is related to the population aging process. This trend is likely to continue in subsequent years. Although clinical outcomes of elderly patients for circulatory system diseases and $\mathrm{HF}$ improved during the past years, the readmission rate still remains high. This indicates that $\mathrm{HF}$ continues to be a major problem in health care. Considering the fact that the readmission reasons in elderly people may be non-cardiac conditions besides HF, both cardiac and non-cardiac conditions should be considered during hospitalizations for HF. Some readmissions may be prevented by the proper selection of medicines and monitoring.

Our study reported the need to determine the measures to decrease HF-related readmission rates. The study provides new information regarding the features and outcomes in elderly patients with HF in Georgia. The study allows us to determine further areas of research for elderly patients with $\mathrm{HF}$.

Conflict of Interest: None

\section{References}

1. World Health Organization [WHO]. Cardiovascular diseases (CVDs): key facts. [updated 2017 May 17; cited 2020 Jun]. Available at: https://www.who.int/news-room/fact-sheets/detail/cardiovasculardiseases-(cvds). 
JHR

36,3

582

2. Georgian Society of Cardiology. Diagnostics and management of chronic heart failure. Tbilisi, Georgia: Georgian Society of Cardiology; 2006.

3. Bibbins-Domingo K, Pletcher MJ, Lin F, Vittinghoff E, Gardin JM, Arynchyn A, et al. Racial differences in incident heart failure among young adults. N Engl J Med. 2009; 360(12): 1179-90. doi: 10.1056/NEJMoa0807265.

4. Teng TH, Finn J, Hobbs M, Hung J. Heart failure: incidence, case fatality, and hospitalization rates in Western Australia between 1990 and 2005. Circ Heart Fail. 2010; 3(2): 236-43. doi: 10.1161/ circheartfailure.109.879239.

5. Levy D, Kenchaiah S, Larson MG, Benjamin EJ, Kupka MJ, Ho KK, et al. Long-term trends in the incidence of and survival with heart failure. N Engl J Med. 2002; 347(18): 1397-402. doi: 10.1056/ NEJMoa020265.

6. Woodham N, Taneepanichskul S, Somrongthong R, Auamkul N. Medication adherence and associated factors among elderly hypertension patients with uncontrolled blood pressure in rural area, Northeast Thailand. J Health Res. 2018; 32(6): 449-58. doi: 10.1108/JHR-11-2018-085.

7. Goldberg RJ, Spencer FA, Farmer C, Meyer TE, Pezzella S. Incidence and hospital death rates associated with heart failure: a community-wide perspective. Am J Med. 2005; 118(7): 728-34. doi: 10.1016/j.amjmed.2005.04.013.

8. Sangprasert P, Palangrit S, Tiyoa N, Pattaraarchachai J. Effects of mindfulness-based health education practice on health behaviors and quality of life among hypertensive patients A quasiexperimental research. J Health Res. 2019; 33(3): 186-96. doi: 10.1108/JHR-07-2018-0059.

9. Verulava T, Jincharadze N, Jorbenadze R. Role of primary health care in re-hospitalization of patients with heart failure. Georgian Med News. 2017; 264(3): 135-9.

10. Metra M, Mentz RJ, Chiswell K, Bloomfield DM, Cleland JG, Cotter G, et al. Acute heart failure in elderly patients: worse outcomes and differential utility of standard prognostic variables. Insights from the PROTECT trial. Eur J Heart Fail. 2015; 17(1): 109-18. doi: 10.1002/ejhf.207.

11. Verulava T, Maglakelidze T, Jorbenadze R. Hospitalization timeliness of patients with myocardial infarction. East J Med. 2017; 22(3): 103-9. doi: 10.5505/ejm.2017.36854.

12. Cleland JG, Daubert JC, Erdmann E, Freemantle N, Gras D, Kappenberger L, et al. The effect of cardiac resynchronization on morbidity and mortality in heart failure. N Engl J Med. 2005; 352(15): 1539-49. doi: 10.1056/NEJMoa050496.

13. Kosiborod M, Lichtman JH, Heidenreich PA, Normand SL, Wang Y, Brass LM, et al. National trends in outcomes among elderly patients with heart failure. Am J Med. 2006; 119(7): 616.e1-7. doi: 10.1016/j.amjmed.2005.11.019.

14. Tuppin P, Cuerq A, de Peretti C, Fagot-Campagna A, Danchin N, Juillière Y, et al. Two-year outcome of patients after a first hospitalization for heart failure: a national observational study. Arch Cardiovasc Dis. 2014; 107(3): 158-68. doi: 10.1016/j.acvd.2014.01.012.

15. Vader JM, LaRue SJ, Stevens SR, Mentz RJ, DeVore AD, Lala A, et al. Timing and causes of readmission after acute heart failure hospitalization-insights from the heart failure network Trials. J Card Fail. 2016; 22(11): 875-83. doi: 10.1016/j.cardfail.2016.04.014.

16. Tuppin P, Cuerq A, de Peretti C, Fagot-Campagna A, Danchin N, Juillière Y, et al. Two-year outcome of patients after a first hospitalization for heart failure: a national observational study. Arch Cardiovasc Dis. 2014; 107(3): 158-68. doi: 10.1016/j.acvd.2014.01.012.

17. Krumholz HM, Wang Y, Mattera JA, Wang Y, Han LF, Ingber MJ, et al. An administrative claims model suitable for profiling hospital performance based on 30-day mortality rates among patients with heart failure. Circulation. 2006; 113(13): 1693-701. doi: 10.1161/circulationaha.105.611194.

18. Dinsdale C, Wani M, Steward J, O’Mahony MS. Tolerability of spironolactone as adjunctive treatment for heart failure in patients over 75 years of age. Age Ageing. 2005; 34(4): 395-8. doi: 10. 1093/ageing/afi104. 
19. American Thoracic Society; Infectious Diseases Society of America. Guidelines for the management of adults with hospital-acquired, ventilator-associated, and healthcare-associated pneumonia. Am J Respir Crit Care Med. 2005; 171(4): 388-416. doi: 10.1164/rccm.200405-644ST.

20. Shah RU, Tsai V, Klein L, Heidenreich PA. Characteristics and outcomes of very elderly patients after first hospitalization for heart failure. Circ Heart Fail. 2011; 4(3): 301-7. doi: 10.1161/ circheartfailure.110.959114.

21. Steinberg BA, Zhao X, Heidenreich PA, Peterson ED, Bhatt DL, Cannon CP, et al. Trends in patients hospitalized with heart failure and preserved left ventricular ejection fraction: prevalence, therapies, and outcomes. Circulation. 2012; 126(1): 65-75. doi: 10.1161/circulationaha.111.080770.

Readmission after hospitalization

\section{Corresponding author}

Tengiz Verulava can be contacted at: tengiz.verulava@gmail.com

For instructions on how to order reprints of this article, please visit our website: 